\title{
Atypical Miyoshi distal myopathy: A case report
}

\author{
MEILING WANG $^{1}$, YUJIE GUO ${ }^{1}$, YONG FU ${ }^{1}$, RUI JIA ${ }^{1}$ and GANG CHEN $^{2}$ \\ Departments of ${ }^{1}$ Neurology and ${ }^{2}$ Interventional Radiology, The Affiliated Hospital of Binzhou Medical University, \\ Binzhou, Shandong 256603, P.R. China
}

Received November 7, 2014; Accepted August 11, 2016

DOI: $10.3892 /$ etm.2016.3716

\begin{abstract}
Five distinct predominant distal myopathies have been identified with discrete clinical and genetic patterns. Miyoshi myopathy (MM; early adult-onset, type 2) is a subtype of dysferlinopathy. Furthermore, MM is the most common form of autosomal recessive distal myopathy. MM is typically characterized by muscular weakness, initially affecting the gastrocnemius or soleus muscle from the late teens or early adulthood. The present study reports a case of MM that was confirmed by pathological and immunohistochemical methods, in addition to a review of the relevant literature. A 37-year-old male patient presented with muscular weakness in the left foot. This clinical manifestation was not typical of MM, and the patient was initially diagnosed with inflammatory myopathy. He was treated with dexamethasone at a dose of $10 \mathrm{mg}$ for 5 days followed by gradual tapering, following which the symptoms were alleviated; however, the pathology, immunohistochemistry and electromyography eventually confirmed the diagnosis of MM. The treatment was then terminated and the patient was discharged. The present study further supports the underlying heterogeneity in atypical MM-like phenotypes. Dysferlin protein deficiency can be identified by pathological examination. The pathology of dysferlinopathy is characterized by changes of muscular dystrophy. Inflammatory cellular infiltration is a relatively common finding in the muscle biopsies from numerous patients with dysferlinopathy. Therefore, the detection of dysferlin deficiency or marked reduction on the sarcolemma using immunohistochemical staining is important for the diagnosis of dysferlinopathy.
\end{abstract}

\section{Introduction}

Dysferlin-deficient limb-girdle muscular dystrophy type 2B (LGMD2B), distal Miyoshi myopathy (MM) and other less

Correspondence to: Miss. Yujie Guo, Department of Neurology, The Affiliated Hospital of Binzhou Medical University, 661 Second Huanghe Road, Binzhou, Shandong 256603, P.R. China

E-mail: guoxiangzhen1984@163.com

Key words: case report, atypical distal Miyoshi myopathy, immunohistochemistry staining frequent phenotypes constitute a group of recessive disorders known as dysferlinopathies. MM with autosomal recessive inheritance and localization to chromosome $2 \mathrm{p}$ is caused by autosomal recessive mutations in the human dysferlin gene $(D Y S F)(1,2)$. In cases of MM, the involvement of the gastrocnemius and soleus muscles, which causes a difficulty in standing on one's tiptoes, is characteristic. Clinical signs usually present for individuals between the late teens and prior to the age of 30 years. According to its clinical and histopathological manifestations, MM has been categorized as a distal myopathy with typical symptoms of muscular dystrophy $(3,4)$. Distal MM is also known as Miyoshi-type distal muscular dystrophy, and was first reported in 1986 by Miyoshi et al (5). Subsequently, an increasing number of cases of MM have been reported, particularly in Japan, Brazil, Finland and South Korea (6-8). In China, there has only been one report of MM in a family in 2004 (9). According to conservative estimates, the incidence of $\mathrm{MM}$ is $\sim 1 / 440,000$ in Japan (10). Among the Jewish population in Libya, 10\% have been found to be carriers of the DYSF gene mutation (1,624 delG), and the incidence of LGMD2B in adults from this population has reached $1 / 1,300(11,12)$. However, the corresponding statistics in China remain unknown.

The present case report describes an atypical MM patient, who was initially misdiagnosed with inflammatory myopathy and finally was diagnosed with MM according to pathology, immunohistochemistry and electromyography.

\section{Case report}

Patient admission and symptoms. This case report was approved by the ethical review committee of the the Affiliated Hospital of Binzhou Medical University (Binzhou, China), and the patient provided informed consent. The patient, a 37-year-old man, was admitted to the Affiliated Hospital of Binzhou Medical University in June 2013 presenting with slowly progressive weakness in the left foot, which was first experienced while driving 1 month prior to admission. Gradually, the patient developed difficulties in standing and walking upstairs when applying pressure on his left foot, which caused him to visit a doctor. The patient had a history of hypertension. There was no relevant family genetic history.

Neurological examination. Neurological examination of the patient revealed normal cranial nerve function and intellectual status. The patient did not exhibit tremor or involuntary 
Table I. Differential diagnosis of common types of distal myopathy.

\begin{tabular}{|c|c|c|c|c|c|}
\hline Variables & $\begin{array}{l}\text { Nonaka } \\
\text { myopathy }\end{array}$ & $\begin{array}{l}\text { Miyoshi } \\
\text { myopathy }\end{array}$ & $\begin{array}{l}\text { Welander } \\
\text { myopathy }\end{array}$ & $\begin{array}{l}\text { Finnish } \\
\text { myopathy }\end{array}$ & $\begin{array}{c}\text { Ophthalmo-pharyngeal } \\
\text { distal myopathy }\end{array}$ \\
\hline Inheritance type & AR & AR & $\mathrm{AD}$ & $\mathrm{AD}$ & $\mathrm{AR}$ or $\mathrm{AD}$ \\
\hline Onset age (years) & $20-30$ & $15-30$ & $>40$ & $>35$ & $<40$ \\
\hline $\begin{array}{l}\text { Main muscles } \\
\text { involved }\end{array}$ & $\begin{array}{l}\text { Anterior leg } \\
\text { muscles }\end{array}$ & $\begin{array}{l}\text { Posterior } \\
\text { calf muscle }\end{array}$ & Upper limb & $\begin{array}{c}\text { Anterior } \\
\text { limb muscles }\end{array}$ & $\begin{array}{c}\text { Extraocular and } \\
\text { bulbar muscles, distal } \\
\text { lower extremities }\end{array}$ \\
\hline Creatine kinase & $<5$-fold & 10-100-fold & $<5$-fold & $<5$-fold & $<5$-fold \\
\hline Rimmed vacuoles & $(+)$ & $(-)$ & $(+)$ & $(+)$ & $(+)$ \\
\hline Dysferlin staining & $(+)$ & $(-)$ & $(+)$ & $(+)$ & $(+)$ \\
\hline
\end{tabular}

$\mathrm{AR}$, autosomal recessive; $\mathrm{AD}$, autosomal dominant.

movements. Muscle tone, muscle strength and sensation were normal. The tendon reflexes were present and symmetrical. No ataxia or abnormal gait was observed.

Laboratory examination. Laboratory examination results showed elevated blood creatine kinase (CK) levels at 4,974.9 U/1 (normal range, 25-200 U/1). Electromyography (EMG) was performed to investigate the origin of the patient's muscle damage. EMG revealed myopathic motor units and recruitment patterns. Initially, the patient's condition was considered to be an inflammatory myopathy and he was treated with dexamethasone (10 mg for 5 days followed by gradual tapering). Following treatment, the CK levels temporarily dropped to 1,493.8 U/1; however, CK levels increased again following the reduction of hormones, reaching 2,698.2 U/1, which suggested that there had been no actual improvement. Pathological examination of the muscle was then performed.

Pathological examination of the muscle. Biopsy tissue obtained from the left quadriceps muscle was precooled in isopentane, frozen in liquid nitrogen, and frozen muscle cross-sections of $8-\mathrm{mm}$ thickness were thereby produced. Routine histological and enzyme activity analyses of the sections were conducted. Immunohistochemical and other types of staining included: Hematoxylin and eosin (H\&E), modified Gomori trichrome (MGT), succinate dehydrogenase (SDH), cytochrome oxidase (COX), Oil Red O (ORO), periodic acid-Schiff staining (PAS), adenosine triphosphatase (ATPase), nicotinamide adenine dinucleotide-tetrazolium reductase (NADH-TR; Fig. 1), dysferlin and dystrophin-C, $-\mathrm{N}$ and $-\mathrm{R}$ staining (Fig. 2).

The muscle fiber size was observed to vary markedly compared with that of healthy muscle tissues. Necrotic and regenerating muscle fibers were observed. No endomysium hyperplasia or inflammatory cell infiltration was observed (H\&E; Fig. 1A). Ragged red muscle fibres or rimmed vacuoles were not shown by the MGT staining (Fig. 1B). Fiber enzyme activity was not reduced (COX; Fig. 1C). Ribosome biogenesis factors and spindle-shaped viruses were not detected (SDH; Fig. 1D). Mesh structure between myofibrils was found to be normal (NADH; Fig. 1E). The glycogen content of muscle fibers was not increased (PAS; Fig. 1F). No lipid droplets were observed within the muscle fibers (ORO; Fig. 1G). Type-I fibers were distributed alternately with type-II fibers. (ATPase; Fig. 1H).

Immunohistochemical staining revealed positive staining for dystrophin-C (Fig. 2A), dystrophin-N (Fig. 2B) and dystrophin-R (Fig.2C) and the total absence of dysferlin labeling along the membrane (Fig. 2D).

In the present study, the pathology of dysferlinopathy was characterized by changes of muscular dystrophy. The detection of dysferlin deficiency or marked reduction on the sarcolemma, as indicated by immunohistochemical staining using anti-dysferlin monoclonal antibody, may thus be used in the diagnosis of dysferlinopathy.

\section{Discussion}

Distal myopathy is a disease characterized by distal limb muscle weakness. According to the onset age, affected muscles and genetic factors, distal myopathy is divided into several subtypes (13).

Congenital defect of dysferlin expression on muscle cell membrane has been suggested to be associated with MM (4), which features a marked increase in blood CK levels, compared with that in other subtypes of distal myopathy. The significant dysferlin protein deficiency of the present case, indicated by immunohistochemical staining of the muscle, suggested distal myopathy. The differential diagnosis criteria of common types of distal myopathy are shown in Table I.

The patient of the present study reported no family history of Miyoshi myopathy. One clinical manifestation in the present case was the inability to stand on tiptoe on the left foot. Progressively, the CK levels in the patient's peripheral blood increased markedly. According to the classification of distal myopathy presented in Table I, these clinical manifestations are suggestive of a diagnosis of distal MM.

$\mathrm{MM}$ is an autosomal recessive disease caused by a DYSF gene mutation, located on chromosome 2p13 (1). Dysferlin protein is encoded by DYSF. The DYSF gene mutation leads to a deficiency of dysferlin proteins, which results 

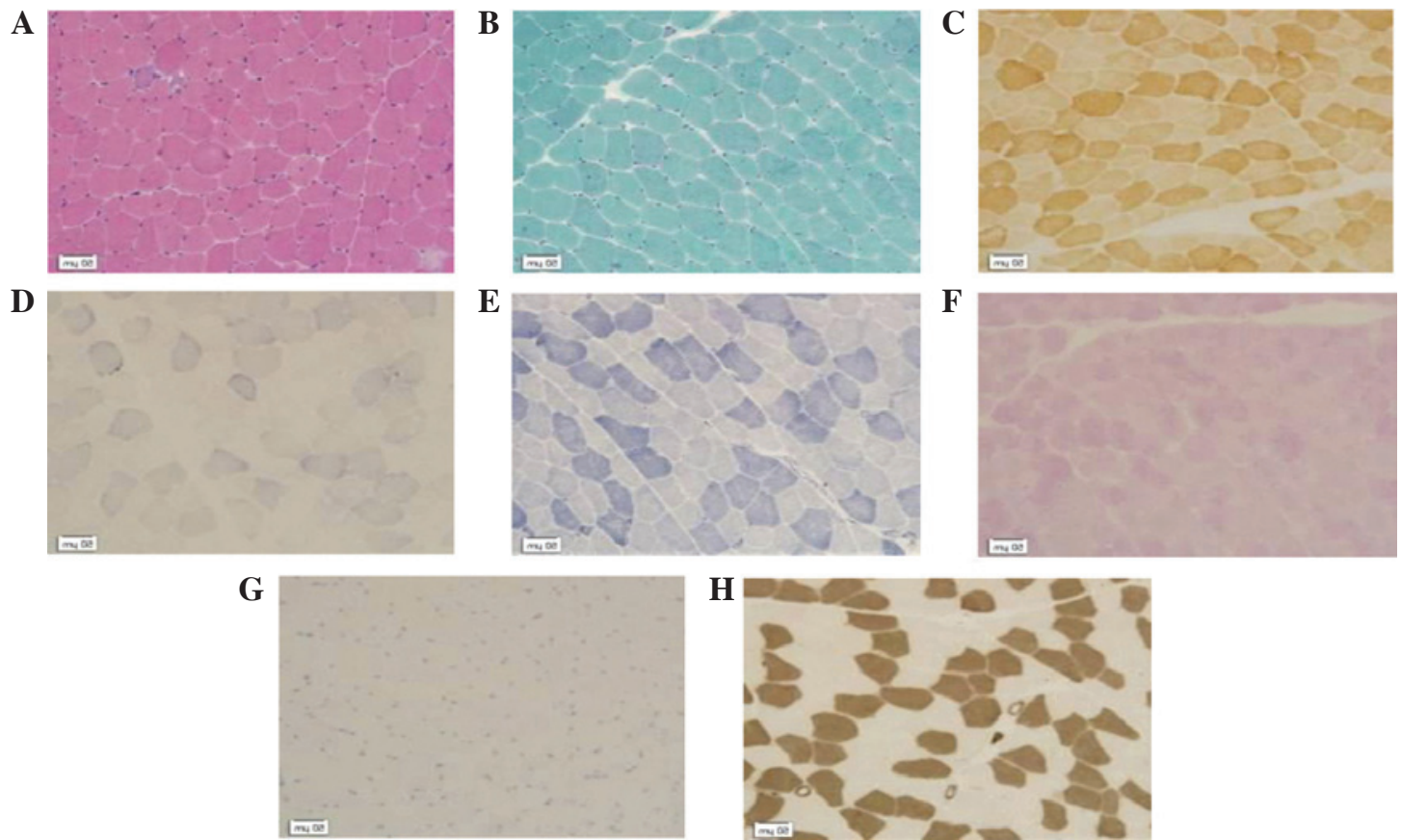

Figure 1. Photomicrographs showing the results of various stains. (A) Muscle fiber size ranged markedly (hematoxylin and eosin staining; magnification, x200). (B) No ragged red muscle fibers, rimmed vacuoles and intramuscular nerve (modified Gomori trichrome staining; magnification, x200). (C) No fiber enzyme activity (cytochrome oxidase staining; magnification, x200). (D) No ribosome biogenesis factors and spindle-shaped viruses (succinate dehydrogenase staining; magnification, x200). (E) Mesh structure between myofibrils was normal (nicotinamide adenine dinucleotide-tetrazolium reductase staining; magnification, x200). (F) Muscle fibers were not increased (periodic acid-Schiff staining; magnification, x200). (G) No increased muscle fibers within the content of lipid droplets (Oil Red O staining; magnification, x200). (H) Two types of fibers distributed alternatively (adenosine triphosphatase staining; magnification, x200).
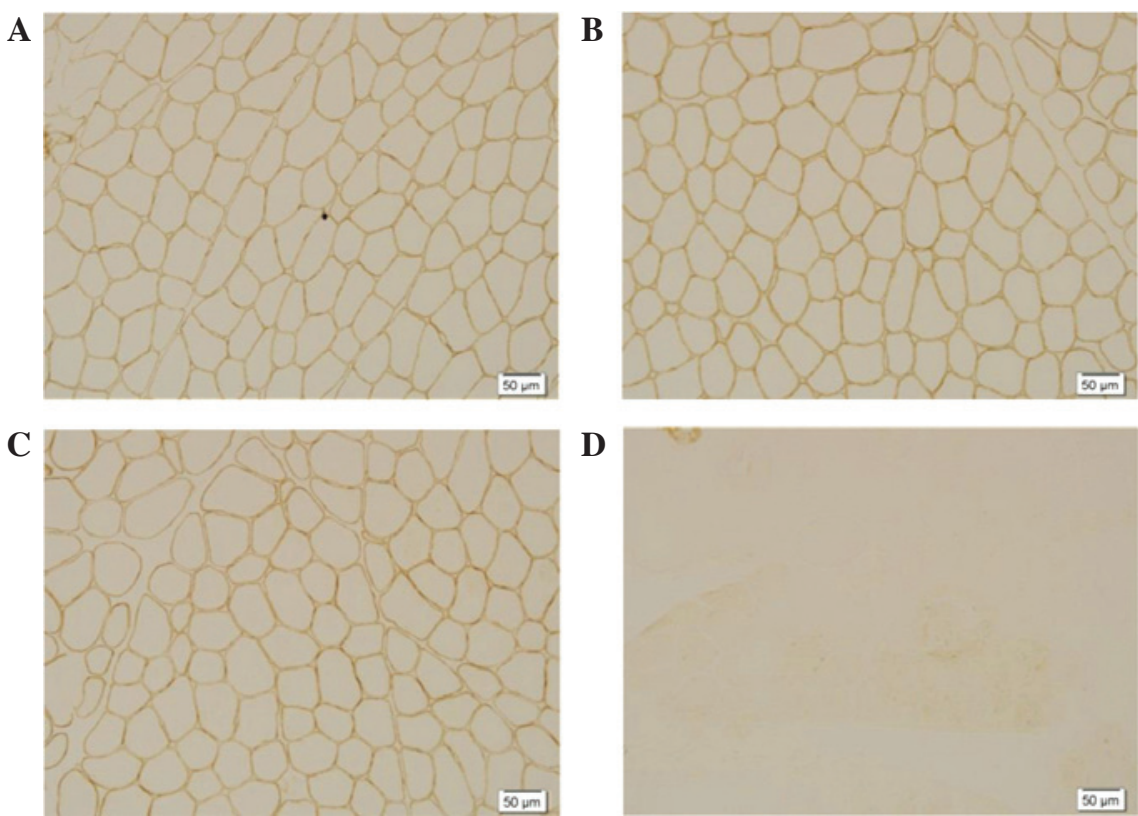

Figure 2. Immunohistochemical staining shows positive (A) dystrophin-C, (B) dystrophin-N and (C) dystrophin-R staining and (D) total absence of dysferlin labeling. Magnification, x200.

in dysferlinopathy. The majority of MM patients present with the initial symptoms between 15 and 30 years of age; but the patients have a broader range of ages of onset (12-36 years) (14). In distal MM, the initial symptoms are in the posterior compartment of the distal lower extremity, which causes an inability to walk on tiptoes or up stairs (15). Pain and discomfort in the calves may also occur (16). The gastrocnemius muscles become atrophic and the stretch reflexes of the ankle muscle are lost (17). The tendency for early involvement of the gastrocnemius muscles has been considered the clinical hallmark of distal MM, which distinguishes it from other distal dystrophies (13). However, muscles of the anterior compartment of the distal lower extremities eventually weaken as well (18). The involvement 
Table II. Clinical phenotypes of dysferlinopathy.

\begin{tabular}{|c|c|c|c|}
\hline Phenotype & Miyoshi myopathy & $\begin{array}{l}\text { Limb-girdle muscular } \\
\text { dystrophy type } 2 \mathrm{~B}\end{array}$ & $\begin{array}{c}\text { Distal anterior } \\
\text { compartment myopathy }\end{array}$ \\
\hline $\begin{array}{l}\text { Major-muscle } \\
\text { involvement }\end{array}$ & $\begin{array}{l}\text { Posterior calf } \\
\text { muscle }\end{array}$ & $\begin{array}{l}\text { Proximal limbs } \\
\text { and calf muscle }\end{array}$ & $\begin{array}{l}\text { Anterior leg } \\
\text { muscles }\end{array}$ \\
\hline \multicolumn{4}{|l|}{ Muscle pathology } \\
\hline In common & Muscle fiber size & Muscle fiber size & Muscle fiber size \\
\hline Differences & Nuclear shift & $\begin{array}{l}\text { Necrotic and regenerating } \\
\text { muscle fibers }\end{array}$ & Nuclear shift \\
\hline Mutated gene & $D Y S F$ gene, located in $2 \mathrm{p} 13$ & $D Y S F$ gene, located in $2 \mathrm{p} 13$ & $D Y S F$ gene, located in $2 \mathrm{p} 13$ \\
\hline Responsible protein & $\begin{array}{l}\text { Dysferlin protein, located in } \\
\text { the muscle fiber membrane, } \\
\text { to repair muscle fiber }\end{array}$ & $\begin{array}{l}\text { Dysferlin protein, located in } \\
\text { the muscle fiber membrane, } \\
\text { to repair muscle fiber }\end{array}$ & $\begin{array}{l}\text { Dysferlin protein, located in } \\
\text { the muscle fiber membrane, } \\
\text { to repair muscle fiber }\end{array}$ \\
\hline Creatine kinase & 30-100-fold & 30-100-fold & 30-100-fold \\
\hline $\begin{array}{l}\text { Muscle immuno } \\
\text {-histochemical staining }\end{array}$ & $\begin{array}{l}\text { Loss of dysferlin } \\
\text { protein staining }\end{array}$ & $\begin{array}{l}\text { Loss of dysferlin } \\
\text { protein staining }\end{array}$ & $\begin{array}{l}\text { Loss of dysferlin } \\
\text { protein staining }\end{array}$ \\
\hline
\end{tabular}

DYSE, dysferlin.

of upper extremities is unusual in the early stages of the disease (16). With the progression of the disease, patients may develop proximal leg and arm weakness to various degrees (16). The hamstring muscle group (knee flexors) may become weaker than the quadriceps muscles (knee extensors), which has implications for the choice of biopsy site (19). Disease progression varies from patient to patient, with some remaining moderately stable with distal weakness, and others presenting a more aggressive pattern, involving both proximal and distal muscles (5). A characteristic laboratory finding of the disease is a marked increase in serum CK levels, up to 20-150-fold above normal (20). In certain cases, an extremely high CK level may be detected during routine blood tests before any clinical weakness or atrophy is present $(21,22)$.

Although dysferlinopathy is caused by a single $D Y S F$ gene, it is well-known that dysferlinopathy has various clinical presentations, such as distal MM, LGMD2B and distal anterior compartment myopathy (Table II). The early involved muscles determine the clinical phenotype of dysferlinopathy. In the present case, the gastrocnemius was the initially involved muscle, which matched the symptoms of MM. In addition, the immunohistochemical analyses, using an anti-dysferlin monoclonal antibody, showed a deficiency or marked reduction in dysferlin on the sarcolemma.

In the present case, a 37-year old male patient presented with the inability to stand on his left foot for 1 month prior to admission to the hospital. Initially, the patient was considered to have inflammatory myopathy, on the basis of an EMG examination. Following treatment with hormone therapy, the CK level temporarily dropped to $1,493.8 \mathrm{U} / 1$, but subsequently increased to 2,698.2 U/1 following the reduction in hormone administration, with no obvious improvement of the symptoms. Subsequently, pathological muscle examinations were conducted. The results of pathological muscle examination, such as the muscle fiber size, and necrotic and regenerating muscle fibers, as well as total absence of dysferlin on the sarcolemma in immunohistochemical staining of muscle, played an important role in diagnosing the patient with dysferlinopathy.

In atypical MM, the following characteristics of the present patient could lead to misdiagnosis: i) The patient was 37 years old, while MM is predominantly observed at a younger age (15-20 years); ii) the onset time was short; 1 month in the present case, in the report by Park et al (14) about typical MM, the course was 2-30 years; iii) the muscle involved was unilateral in the present patient, but in the reports by Wang et al (16), Zhang et al (17) and Gayathri et al (23) typical MM was bilateral; and iv) the present case was sporadic; however, typically MM is a rare autosomal recessive inherited myopathy and sporadic cases are uncommon.

Due to certain pathological features that are observed in cases of MM, such as muscle weakness, elevation of $\mathrm{CK}$ levels and mononuclear cell infiltration, it is not rare for the disease to be misdiagnosed as inflammatory myopathy. A previous study found that certain patients with MM also present with gastrocnemius muscle myalgia, swelling and even false hypertrophy at the early stage of the disease (12). The pathogenesis of these symptoms is not clear and may be associated with transient inflammatory reaction. The early symptoms of MM are not typical and are readily misdiagnosed; therefore, the pathological muscle examination should be undertaken as soon as possible. In particular, immunohistochemical staining including anti-dysferlin monoclonal antibodies may be useful for the identification of possible dysferlin deficiency.

\section{Acknowledgements}

This study was supported by a grant from the Science and Technology Planning Program of Binzhou Medical 
University of China (grant. no. BY2012KJ03) and the Science and Technology Development Planning Program of Binzhou City (grant. no. 2014ZC0144).

\section{References}

1. Weiler T, Greenberg CR, Nylen E, Halliday W, Morgan K, Eggertson D and Wrogemann K: Limb-girdle muscular dystrophy and Miyoshi myopathy in an aboriginal Canadian kindred map to LGMD2B and segregate with the same haplotype. Am J Hum Genet 59: 872-878, 1996.

2. Liu J, Aoki M, Illa I, Wu C, Fardeau M, Angelini C, Serrano C, Urtizberea JA, Hentati F, Hamida MB, et al: Dysferlin, a novel skeletal muscle gene, is mutated in Miyoshi myopathy and limb girdle muscular dystrophy. Nat Genet 20: 31-36, 1998 .

3. Nonaka I: Distal myopathies. Curr Opin Neurol 12: 493-499, 1999.

4. Mastaglia FL, Lamont PJ and Laing NG: Distal myopathies. Curr Opin Neurol 18: 504-510, 2005.

5. Miyoshi K, Kawai H, Iwasa M, Kusaka K and Nishino H: Autosomal recessive distal muscular dystrophy as a new type of progressive muscular dystrophy. Seventeen cases in eight families including an autopsied case. Brain 109: 31-54, 1986.

6. Tagawa K, Ogawa M, Kawabe K, Yamanaka G, Matsumura T, Goto K, Nonaka I, Nishino I and Hayashi YK: Protein and gene analyses of dysferlinopathy in a large group of Japanese muscular dystrophy patients. J Neurol Sci 211: 23-28, 2003.

7. Oh SH, Kang SW, Lee JG, Na SJ, Kim TS and Choi YC: Clinical and pathological characteristics of four Korean patients with limb-girdle muscular dystrophy type 2B. J Korean Med Sci 19: 447-452, 2004.

8. Vainzof M, Anderson LV, McNally EM, Davis DB, Faulkner G, Valle G, Moreira ES, Pavanello RC, Passos-Bueno MR and Zatz M: Dysferlin protein analysis in limb-girdle muscular dystrophies. J Mol Neurosci 17: 71-80, 2001.

9. Sun SC, Fan ZS, Wu HC, Leturcq F, Zhang BF, Yu W, Deburgrave N, Liu M and Song YJ: Dysferlin deficiency: The cause of limb-girdle muscular dystrophy $2 \mathrm{~B}$ and Miyoshi myopathy in a Chinese pedigree. Zhonghua Yi Xue Yi Chuan Xue Za Zhi 21: 128-131, 2004 (In Chinese).

10. Bejaoui K, Hirabayashi K, Hentati F, Haines JL, Ben Hamida C, Belal S, Miller RG, McKenna-Yasek D, Weissenbach J and Rowland LP: Linkage of Miyoshi myopathy (distal autosomal recessive muscular dystrophy) locus to chromosome $2 \mathrm{p} 12-14$ Neurology 45: 768-772, 1995.
11. Bashlr R, Strachan T, Keers S, Stephenson A, Mahjneh I, Marconi G, Nashef L and Bushby KM: A gene for autosomal recessive limb-girdle muscular dystrophy maps to chromosome 2p. Hum Mol Genet 3: 455-457, 1994.

12. Argov Z, Sadeh M, Mazor K, Soffer D, Kahana E, Eisenberg I, Mitrani-Rosenbaum S, Richard I, Beckmann J, Keers S, et al: Muscular dystrophy due to dysferlin deficiency in Libyan Jews Clinical and genetic features. Brain 123: 1229-1237, 2000.

13. Barohn RJ, Amato AA and Griggs RC: Overview of distal myopathies: From the clinical to the molecular. Neuromuscul Disord 8: 309-316, 1998.

14. Park HJ, Hong JM, Suh GI, Shin HY, Kim SM, Sunwoo IN, Suh BC and Choi YC: Heterogeneous characteristics of Korean patients with dysferlinopathy. J Korean Med Sci 27: 423-429, 2012.

15. Miyoshi K, Kawai H, Iwasa M, Kusaka K and Nishino H: Autosomal recessive distal muscular dystrophy as a new type of progressive muscular dystrophy. Seventeen cases in eight families including an autopsied case. Brain 109: 31-54, 1986.

16. Wang M, Zuo YW, Lu Y, Xu M, Liu Z and Jia JP: Clinical and pathological features of Miyoshi myopathy with dysferlin protein deficient. Lin Chuang Shen Jing Bing Xue Za Zhi 22: 16-18, 2009 (In Chinese).

17. Zhang LR, Hu J, Zhao Z, Li N, Shen HR and Bing Q: An analysis of clinical features and pathology in 40 patients with dysferlinopathy. Zhonghua Shen Jing Ge Za Zhi 46: 438-442, 2013 (In Chinese).

18. Ueyama H, Kumamato T, Horinouchi H, Fujimoto S, Aono H and Tsuda T: Clinical heterogeneity in dysferlinopathy. Intern Med 41: 532-536, 2002.

19. Barohn RJ, Miller RG and Griggs RC: Autosomal recessive distal dystrophy. Neurology 41: 1365-1370, 1991.

20. Aoki M, Liu J, Richard I, Bashir R, Britton S, Keers SM, Oeltjen J, Brown HE, Marchand S, Bourg N, et al: Genomic organization of the dysferlin gene and novel mutations in Miyoshi myopathy. Neurology 57: 271-278, 2001

21. Galassi G, Rowland LP, Hays AP, Dimauro S and Hopkins LC: High serum levels of creatine kinase: Asymptomatic prelude to distal myopathy. Muscle Nerve 10: 346-350, 1987.

22. Linssen WH, Notermans NC, Van der Graaf Y, Wokke JH, Van Doorn PA, Höweler CJ, Busch HF, De Jager AE and De Visser M: Miyoshi-type distal muscular dystrophy. Clinical spectrum in 24 Dutch patients. Brain 120: 1989-1996, 1997.

23. Gayathri N, Alefia R, Nalini A, Yasha TC, Anita M, Santosh V and Shankar SK: Dysferlinopathy: Spectrum of pathological changes in skeletal muscle tissue. Indian J Pathol Microbiol 54: 350-354, 2011. 